\title{
How the brain controls all pleasures including sex, food, drugs, rock 'n roll and others
}

SADJ June 2019, Vol. 74 No. 5 p243

Author: Professor Mark Alfred Gillman

Publisher: Cerebrum

605 pages in the Kindle version. 10 chapters; 6 Illustrations; 436 references.

This is not a book to be read in one sitting... although it is compulsive reading! That paradox is reflected through the pages as Professor Mark Gillman takes the reader on a fascinating journey founded on the paradox that without pain, there can be no pleasure! But the focus is firmly on the pleasure side of the equation, delving into the many ways in which humans may enjoy pleasure.

Mark brings to this book all of his many years of remarkable exploration into the byways and pathways of the human brain. Steeped as he is with an intricate knowledge of the complexities of the brain, it must have been a major challenge for Professor Gillman to reduce and compress that acumen into a most readable ten chapters dealing with aspects of the sources and control of that most human of endeavours... the pursuit of pleasure.

That challenge has been met most effectively by the author who, as an accomplished wordsmith, has produced an intriguing and logical exposition of the continuum of pain and pleasure, a concept which was the result of long term cooperation and liaison with a psychiatrist, Dr Fred Lichtigfeld... but the read itself is essentially Gillman.

The reader is introduced to the basics of brain anatomy and function, the text being well supported by informational diagrams of considerable clarity.

The pathways of pleasure are described together with the controlling chemical interactions... always on a level to ensure understanding by the lay reader whilst stimulating the interest of the more involved professional.

Then commences the opportunity for illuminating debate on the variety of pleasures sought after by Man. Dealt with are Drugs, Gambling, Eating, Sex, Computer, Shopping, Dancing and other addictions. An innovative touch is introduced by the inclusion of Health Tips at the conclusion of each chapter.

The text evaluates relevant research and balances opposing views dispassionately and fairly, acknowledging the gaps in knowledge. The author is excited about the future unravelling of some of the dilemmas. Indeed he may be instrumental in some of that elucidation!

This is a book to be savoured, chewed over, contemplated, debated. It is an intriguing read for all having even a remote interest in what motivates and drives us to seek the pleasurable. Sit back and enjoy the pleasure!

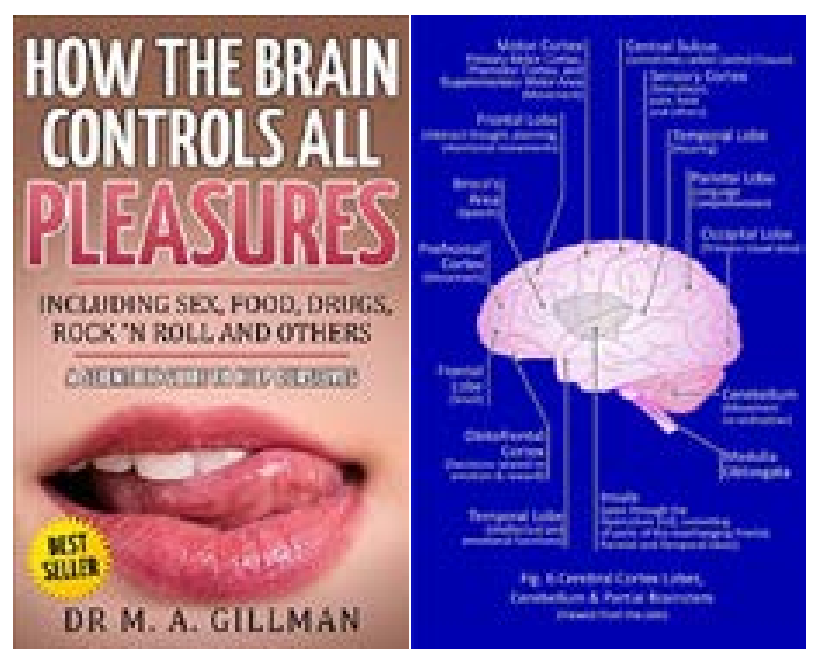

The Author

Professor Gillman lists more than 300 publications in scientific journals, has lectured internationally, held positions at the University of the Witwatersrand, at Medunsa and at the Albert Einstein Medical Science University. He is Emeritus Director of The South African Brain Research Institute, where he and Dr Lichtigfeld made seminal contributions. He is also the author of several books.

$B E$ 